DAVI RODNEY SILVA

№ USP 9739528

\title{
NEUROCIÊNCIA E CULPABILIDADE
}

\author{
Dissertação de Mestrado \\ Orientador: Prof. Dr. Roberto Augusto de Carvalho Campos
}

UNIVERSIDADE DE SÃO PAULO

FACULDADE DE DIREITO

São Paulo - SP

2019 

DAVI RODNEY SILVA

\section{NEUROCIÊNCIA E CULPABILIDADE}

Dissertação de Mestrado

Dissertação de Mestrado apresentada ao Departamento de Direito Penal, Medicina Forense e Criminologia da Faculdade de Direito da Universidade de São Paulo, como requisito parcial para a obtenção do título de Mestre em Direito.

Orientador: Prof. Dr. Roberto Augusto Carvalho Campos.

UNIVERSIDADE DE SÃO PAULO

FACULDADE DE DIREITO

São Paulo - SP

2019 

Davi Rodney Silva

\section{Neurociência e Culpabilidade}

Dissertação de Mestrado apresentada ao Departamento de Direito Penal, Medicina Forense e Criminologia da Faculdade de Direito da Universidade de São Paulo, como requisito parcial para a obtenção do título de Mestre em Direito.

Aprovado em:

\section{Banca Examinadora}

Orientador: Prof. Dr. Roberto Augusto Carvalho Campos

Professor(a):

Julgamento: Assinatura: 



\section{AGRADECIMENTOS}

Ser grato é, ou deveria ser, o ato humano por excelência. No meu caso, lamento nem sempre externar esse sentimento com palavras, e peço desculpas se, ao fazê-lo neste espaço, possa perecer hipócrita. Mas espero, também, que as linhas dedicadas nesse singelo trabalho não sejam a forma com que melhor minha pessoa exprima a gratidão àqueles que positivamente me cercam.

Primeiramente, agradeço à minha família, por ter me ensinado a viver com o material escasso que tinha disponível, e por me fazer entender que a meritocracia não é algo a ser exaltado acima de tudo em ambiente inóspito e desigual.

Sou imensamente grato ao meu Professor orientador, Doutor Roberto Augusto de Carvalho Campos, por ter sido paciente enormemente com os percalços que tive de trilhar no período de orientação: muito obrigado!

Aos amigos, claro, que me têm apoiado desde sempre, em especial ao Daniel Vieira de Jesus, pessoa de todas as horas, lugares e situações; à Vivian Marcella Cunha, minha amiga, minha irmã, minha conselheira e mãe dos meus sobrinhos, que, mesmo distante, está em mim; ao trio mais caloroso dos meus laços: Caroline Ide, Daniela Marques e Emily Oliveira, agradeço pela amizade, apoio e por terem sobrevivido ao tempo; ao Israel da Silva Santos, amigo de infância e certamente de velhice; ao círculo formado por Priscila Lino, Patrícia Campos, Mônica Evangelista, Renata Sampaio, Alexandre de Macedo e Rejane lodjhn, por terem me recebido de braços abertos nos últimos anos. À Mariana Bertolo, por me dar companhia e afago durante todo o trajeto dessa dissertação. E à Paula Machado, por aparecer no último e mais importante momento da pesquisa.

Pela amizade nascida dos laços profissionais, agradeço ao Professor João Daniel Rassi, que me ensinou quase tudo que sei; à Mariana Tranchesi Ortiz, minha madrinha no Direito Penal, que me fez evoluir a partir do seu rigor e inteligência; ao Professor Jorge Coutinho Paschoal, a mente brilhante que habita um ser carismático e divertido; e àquele que me fez convencer que eu era capaz de cursar este importante caminho da vida acadêmica e que apenas posso adjetivar de irmão: Gilberto Alves Junior. 
À minha mãe e aos meus irmãos, com amor dedico este trabalho, que também é deles.

Lilian, Washington, Alexandre, Daniel e Ana Paula 


\section{RESUMO}

O presente trabalho tem por escopo analisar e conjugar dois temas discutidos pelas literaturas jurídico-penal e médica com certa dedicação nos últimos anos: o instituto da Culpabilidade e as Neurociências, respectivamente.

Sabe-se que a Culpabilidade, pressuposto de aplicação de uma reprimenda penal, consiste em verdadeiro termômetro da democracia de direito das nações e, por esse motivo, todo e qualquer tema que Ihe faça fronteira merece especial atenção, como é o caso das Neurociências.

Desse modo, a dissertação, após fazer um traçado histórico sobre a Culpabilidade, chegando em seu conceito atual mais difundido, buscará demonstrar que o instituto é embasado no pressuposto do livre-arbítrio, sua coluna sustentadora, passando a confrontar esse aspecto sob a ótica dos experimentos neurocientíficos formulados por Benjamin Libet, na busca de responder à seguinte questão: é possível a compatibilização entre as proposições neurocientíficas iniciais de Benjamin Libet e a legitimação da aplicação da pena tendo a Culpabilidade como condição e o livrearbítrio como pressuposto?

Palavras-chave: Culpabilidade; Neurociências; Livre-arbítrio. 


\begin{abstract}
The following paper analyzes and gathers information regarding two issues discussed by criminal law and medical literature, with extra attention over the past years: Culpability and Neuroscience, respectively.

Culpability, which defines the application of criminal reprimands, is known as a true thermometer of nations' democracy; for that reason, every single field that might cover and enhance this subject deserves special attention, which is exactly the case when we are talking about Neuroscience.

That being said, this dissertation has historically analyzed the fundamentals of Culpability, reaching its current widespread concept, demonstrating how Culpability is based on the assumption of the free will concept, the foundation of Culpability, confronting this aspect with the Neuroscience perspective. This paper will seek to respond to the following question: is it possible to align the initial neuroscienfic propositions of Benjamin Libet with the legitimization of criminal reprimand application having Culpability as a condition and free will as a preassumption?
\end{abstract}

Key-words: Culpability; Neurosciences; Free will. 


\section{LISTA DE FIGURAS}

Figura 1 - Compatibilidade do livre-arbítrio com a onisciência .80 Fonte: Produção do próprio autor.

Figura 2 - Face do Oscilloscope 96

Fonte: Disponível em <https://bit.ly/2m9GN3J>. Acesso em abril 2019.

Figura 3 - Gráfico da ativação neuronal

Fonte: Disponível em < https://bit.ly/2maCBAN >. Acesso em abril 2019.

Figura 4 - A decisão inconsciente no cérebro. 101

Fonte: Disponível em <https://www.mpg.de/research/unconscious-decisions-in-thebrain>. Acesso em maio 2019. 



\section{SUMÁRIO}

1. Introdução.

2. Da necessária exposição da metodologia a ser utilizada: as diferenças de enfoques existentes entre ciências médicas e sociais.

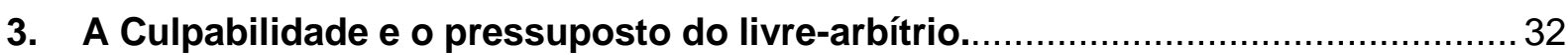

3.1. Os primórdios da culpabilidade: as sociedades primitivas............................. 33

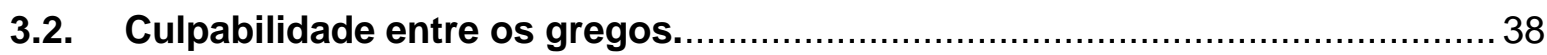

3.3. Culpabilidade entre os povos germânicos. ..................................................... 40

3.4. A Culpabilidade no Direito Romano. ........................................................ 43

3.5. A Culpabilidade e o livre-arbítrio na Idade Média ocidental: do Feudalismo ao

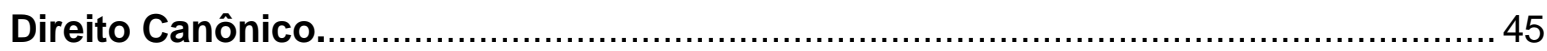

3.6. A Culpabilidade no Direito Penal moderno e contemporâneo. ........................ 48

3.6.1. A evolução dogmática da Culpabilidade................................................ 48

3.6.2. Panorama geral da Culpabilidade nas Escolas Penais............................. 49

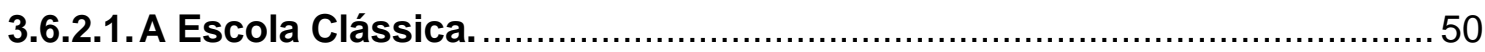

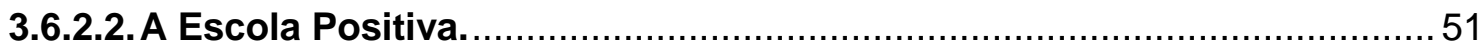

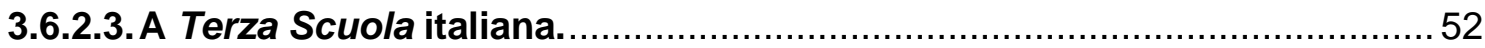

3.6.2.4. A Escola Moderna Alemã........................................................................ 53

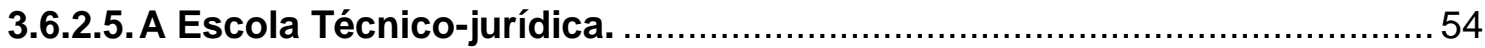

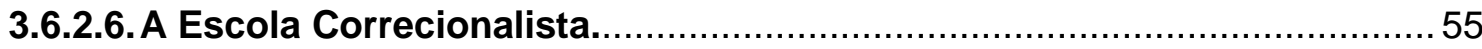

3.6.3. Os aspectos subjetivos e normativos contemporâneos da Culpabilidade.

4. Na Culpabilidade: os aspectos subjetivos da conduta humana e o pressuposto do

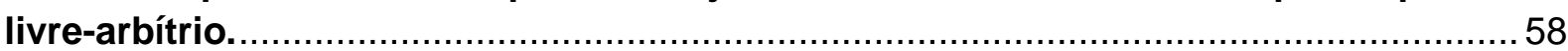

4.1. O pressuposto do livre-arbítrio como base da Culpabilidade........................59

4.1.1. A questão da liberdade como condição do livre-arbítrio..........................61

4.1.2. Livre-arbítrio como questão filosófica: aceitação ou negação do dualismo cartesiano.

4.2. O livre-arbítrio como questão filosófico-religiosa........................................ 71

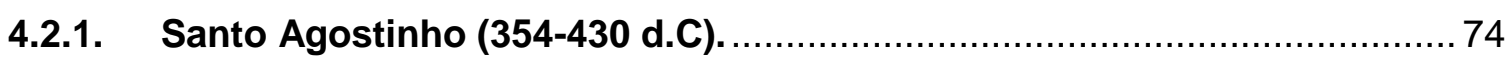

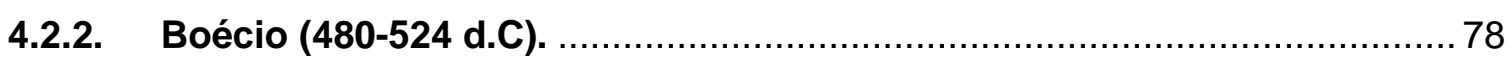

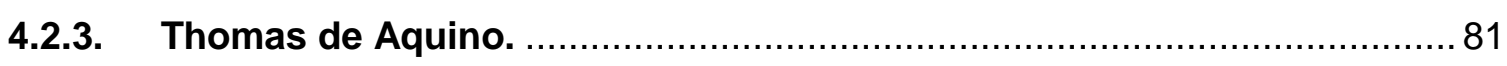

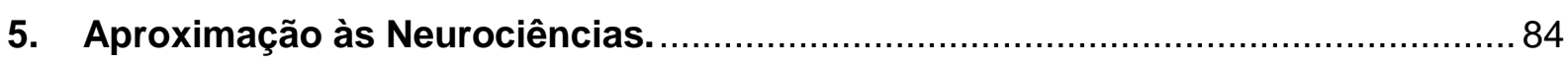


5.1. Sobre o método cientifico como pressuposto: as ciências construtivistas. .. 84

5.2. Considerações iniciais sobre as Neurociências. 89

5.3. Neurociências e o funcionamento neuronal inconsciente. 92

5.3.1. O funcionamento neuronal inconsciente de Benjamin Libet. 93

5.3.2. O método experimental de Benjamin Libet. 94

5.3.3. A confirmação pelo experimento de John Dylan Haynes. 100

5.3.4. Considerações sobre as hipóteses de Libet e Haynes. 102

6. Conclusão. 107

7. Bibliografia. 


\section{Introdução.}

O presente trabalho tem por objeto dois assuntos principais e um ponto conector que os questiona e projeta. Nessa interface, pode-se afirmar que a dissertação visa a trabalhar conceitos já tradicionais de Direito material, agora revisitados, assim como contemporâneos e de vanguarda.

Nesse sentido, parte-se do tradicionalíssimo instituto de Direito Penal da Culpabilidade e seus corolários, sem se olvidar do conteúdo que se lhe tem dado ao longo dos anos. Entendido como pressuposto de distribuição de responsabilidade nos mais variados ordenamentos jurídicos, referido instituto tem se alçado como verdadeiro termômetro da prática democrática no seio social, porquanto tem o condão de limitar, legitimar e justificar a intervenção estatal na esfera de maior importância aos indivíduos.

Todavia, a despeito de sua inegável autoridade, o desenvolvimento da dissertação não toma a Culpabilidade e suas premissas como absolutas. Antes, questiona-as, arrancando-Ihe à fórceps indagações acerca de importante elemento de sua constituição: o livre-arbítrio, sobretudo em sua face dicotômica cartesiana.

Não se tratam, no entanto, de questionamentos de toda ordem, senão aqueles provenientes das Neurociências e mais especificamente dos experimentos de Libet. Enquanto a Culpabilidade será abordada como o primeiro tema principal, as Neurociências podem ser identificadas como o ponto que a ela se conectará para questionar e elaborar hipóteses.

À evidência, o estudo conjugado da Culpabilidade e das Neurociências já não é novidade, seja em terreno estrangeiro ou nacional. Não se tem, pois, apenas o intuito de revisitar os temas e reproduzir ou atualizar o que vem sendo abordado pela comunidade acadêmica.

Com efeito, as análises de Benjamin Libet se elevam, nessa dissertação, a um ponto de confluência, indagação e condicionante, porquanto visa, ao mesmo tempo, a questionar o livre-arbítrio e sua serventia a fundamentar a Culpabilidade tal como entendida atualmente. 
Pois bem. Resta, no entanto, enfatizar que a dissertação fará fronteiras com conceitos adjacentes aos temas centrais, tal qual a teoria do crime, sem que com eles se confunda, para que a questão central não se perca. Por outro lado, é necessário igualmente sobrelevar que a limitação do desenvolvimento do trabalho identifica-se com as incertezas no que concerne aos estudos de Libet e das próprias Neurociências.

De fato, embora seja palpável a rápida evolução nessa área de estudo, precipuamente com o acesso que atualmente se tem ao cérebro, com tecnologia extremamente sofisticada, parece-nos que o plantel formado pelas diversas frentes das Neurociências está longe de constituir uma verdadeira "revolução neurocientífica" capaz de alterar significativamente o paradigma jurídico da Culpabilidade ${ }^{1}$.

É que, para além dos percalços culturais e políticos, ainda há muito que se desenvolver em termos científicos para que a eventual virada seja necessária ou pelo menos possibilitada. No mesmo raciocínio, é também essa amálgama de teorias e abordagens das Neurociências, com substanciais alterações em termos temporais sobre as hipóteses por elas mesmas levantadas, que reside a maior limitação do tema.

Isto porque, em termos neurocientíficos, o material atinente à existência ou não do livre-arbítrio (capaz de fazer frente à Culpabilidade), assim como em relação às causas determinantes do agir humano é ainda incerto e somente pode gerar probabilidades, com as quais esta dissertação pretenderá trabalhar.

Desse modo, pisando ainda em solo instável, a monografia tem por objetivo discorrer sobre o instituto da Culpabilidade e, à luz dos estudos de Libet, questionar e projetar uma possível compatibilização de eventual futura revolução neurocientífica com relação à distribuição de responsabilidade em sede de Direito Penal.

A importância do tema, que configura também a justificativa de sua escolha, pode ser identificada nos três principais pontos que o compõem, ainda que por motivos diversos, ao nosso sentir.

\footnotetext{
${ }^{1}$ Cf. CRESPO, Eduardo Demetrio in Neurociencias y Derecho penal: nuevas perspectivas en el ámbito de la culpabilidad y tratamiento jurídico-penal de la periculosidad.Demetrio Crespo, Eduardo (dir.) MarottoCatalayud, Manuel (coord.). Montevideo: B. de F., 2013, p. 19.
} 
A Culpabilidade é sobrelevada pelo próprio papel que desempenha para o Direito Penal, podendo-se afirmar que se trata de uma de suas principais bases de sustentação, ao passo que está imbuída de justificar a distribuição de responsabilidades pela face mais incisava do Estado, subjugando direitos dos mais intrínsecos e caros aos cidadãos.

Neste passo, tem-se afirmado que a análise do grau de democracia de um Estado passa inevitavelmente pelo seu ordenamento jurídico-penal, notadamente no que toca ao manuseio da Culpabilidade como pressuposto e instituto limitador da distribuição da responsabilidade dos indivíduos e, consequentemente, da aplicação de uma sanção de cunho penal.

De fato, o instituto tem se destacado para muito além do afastamento da responsabilidade objetiva e da exigência prévia de lei que permita ao cidadão conhecer a ilicitude de uma conduta estampada em um tipo penal - política esta vigente desde o século XIX². Ganhou, por sua importância, autonomia na estrutura formadora do crime.

Clarividente que se trata de um instituto legitimador cuja edificação deve procurar estar sempre alinhada com a melhor técnica dogmática, sem se olvidar, no entanto, de atender a anseios de origem política e social.

É que, para nós, de fato, a Culpabilidade jamais teve um conteúdo puramente técnico-científico, sendo ele erigido para atender a expectativas sociais e de políticas criminais. Isto fica ainda mais patente com o rechaço que se tem normalmente dado a possíveis aportes de áreas como as Neurociências, cuja validade poderia colocar em cheque essas mesmas "finalidades" sociais e políticas.

Com efeito, apesar de toda altivez desse importante instituto de Direito Penal, deve-se questionar sobre a possibilidade de se abrir caminho, não sem críticas, às influências externas, ainda que isso signifique a desconstrução de suas premissas basilares. Não se pode dar de ombros a evidências com a justificativa de que a punição criminal restaria inviável.

\footnotetext{
${ }^{2}$ FLORÊNCIO FILHO, Marco Aurélio. Culpabilidade: crítica à presunção absoluta do conhecimento da lei penal. São Paulo: Saraiva, 2017, p. 15.
} 
Caso as Neurociências tenham o condão de afastar, cientificamente, a ideia do dualismo cartesiano e, portanto, a existência do livre-arbítrio - e aqui pode ser identificada a importância desse segundo grande tema - haverá de se encontrar outros meios de atender as expectativas políticas e sociais, mas sempre sem subjugar a condição humana e os direitos que lhe são imanentes.

É de toda precipitada a hesitação sobre os novos aportes científicos sob o subterfúgio de um suposto Direito Penal de medidas. Se a liberdade de agir como entendida hoje for afastada por estudos neurocientíficos, deve-se antes pensar no equívoco com que se vinha aplicando o instituto da Culpabilidade, e não apenas tentar salva-lo com vistas a viabilizar a teoria do crime.

Por mais que se tenha desenvolvido trabalhos sobre uma possível compatibilização entre o Direito Penal e as Neurociências, acadêmicos esforçam-se por rechaçar os conhecimentos destas últimas a pretexto de salvar a forma como se tem divisado responsabilidades em imposto penas. Demetrio $\mathrm{Crespo}^{3}$, por exemplo, citando Hirsch, lembra que:

Son muchos los autores que han criticado las consecuencias a las que podría conducir el "determinismo fuerte" en el Derecho penal si aboliéramos de nuestro universo conceptual toda referencia a la voluntariedad de las conductas y a la noción de responsabilidad. Aunque no siempre afortunadas o exactas algunas de esas criticas, apuntan a una conclusión poco discutible: un Derecho penal sin libertad humana equivaldria a un Derecho penal sin culpabilidad, lo que dejarla paso a un Derecho (penal) de medidas de seguridad.

Ora, parece-nos que, se houver evidências suficientes que desmontem o livrearbítrio tal qual conhecemos hoje, dando lugar a um determinismo, seja este em qual intensidade for, o Direito Penal deve admitir o erro pelo qual percorreu durante muito tempo, assim como já o fez em relação a outras tantas figuras que se lhe relacionavam.

Não se trata de sumariamente reconhecer a validade dos conhecimentos advindos das Neurociências, tampouco descreditar a importância da Culpabilidade para o Direito Penal. Ao contrário, exatamente por sua importância, por tudo o que

\footnotetext{
${ }^{3}$ CRESPO, Eduardo Demetrio in Neurociencias y Derecho penal: nuevas perspectivas en el ámbito de la culpabilidad y tratamiento jurídico-penal de la periculosidad. Demetrio Crespo, Eduardo (dir.) MarottoCatalayud, Manuel (coord.). Montevideo: B. de F., 2013, p. 29/30.
} 
representa para a função de distribuir responsabilidades e penas, é que se deve levar a sério qualquer conhecimento que Ihe faça fronteira, seja para reforçar e, principalmente, para afastar os elementos que the dão suporte, como o livre-arbítrio.

Talvez, melhor um Direito Penal de medidas assim conhecido e difundido - 0 que possibilitaria, inclusive, a formação de novas linhas de pesquisa -, que a manutenção de bases insólitas com a justificativa de se estar "viabilizando" a aplicação de penas.

Desse modo, mostra-se clara a importância de abordar de forma séria, mas não apaixonada, a influência ainda que projetada das Neurociências sobre as colunas sustentadoras da Culpabilidade, sobretudo se forem reafirmadas as hipóteses que propõem um determinismo, extremado ou não. O contato das Neurociências, aqui, está voltado para cima, onde encontrará a Culpabilidade como uma figura que as antecede e por elas será confrontada.

Nesse sentido, busca-se neste trabalho fazer uma projeção de consequências que sobrevirão em caso de aceitação das propostas científicas de Benjamin Libet em terreno atualmente ocupado pelo livre-arbítrio: direito penal de medidas? De conveniência?

Com efeito, a par dos novos aportes neurocientíficos, tem-se sugerido que o funcionamento cerebral, em especial no que toca à liberdade de escolha de ação, está assentado exclusivamente em aspectos físico-biológicos, é dizer, sem qualquer denotação metafísica que dê suporte ao livre-arbítrio. Libet representa, no conjunto de seus experimentos, um meio termo entre o físico e o metafísico, como se verá.

De outra banda, a motivação, o start desse funcionamento, as suas condicionantes, estão, dentre outros, baseados na formação social do indivíduo, o qual, agora, para os neurocientistas, não é totalmente imune a pontos de contato com o seio social. Isto é, por não estar mais situado no plano imaterial, o processo volitivo afigura-se mais vulnerável a essas influências.

Não se pretende, todavia, alienar o ser humano a tal ponto de torna-lo irresponsável, simples objeto de joguete e vítima de seu próprio cérebro. Também não se tem o condão de deslegitimar a atuação do Estado e destituir-Ihe de seu famigerado direito/dever de punir. 
Ao contrário, tendo sempre a sociedade como algo a ser protegido e sobrelevado, mas sem perder de vistas os indivíduos que a compõem, tem-se por objeto rediscutir antigos conceitos, analisar outros que vêm sendo desenvolvidos, e projetar um futuro que os compatibilize de tal forma que não se desrespeite, um segundo sequer, o Estado Democrático de Direito e, consequentemente, direitos e garantias individuais.

A importância do tema, portanto, e que justifica a sua escolha, não toca apenas ao mero estudo de institutos de Direito Penal e aos conhecimentos neurocientíficos. No fundo, trata-se, a nosso ver, de uma abordagem que visa a trazer à baila a indissociável proteção que se deve dispensar, sempre e sempre, à sociedade, como um todo, e a cada um de seus membros, individualmente, como sói acontecer mediante a correta aplicação da lei, notadamente a de cunho penal.

A intervenção do Estado na esfera privada de um indivíduo constitui um tema de estudo tormentoso e há séculos tem fomentado dezenas de teorias que visam a explicar, justificar e, sobretudo, fundamentar e legitimar a necessidade de se criar preceitos dirigidos aos membros de uma coletividade, assim como a imposição de uma consequência negativa para quem deles se desvie.

Isso pode ser observado em todos os graus de uma organização social, desde a própria existência do Estado ${ }^{4}$, passando pelas formas de governo, até a própria edificação das instituições que lhe dão suporte, aí se incluindo o Direito, tido como uma de suas mais importantes bases de sustentação.

Aprofundando-se um pouco mais, pode-se dizer que na constituição do ordenamento jurídico de uma sociedade, seja ele codificado ou não ${ }^{5}$, o Direito Penal

\footnotetext{
${ }^{4}$ Embora não seja objeto do presente estudo, no que se refere à formação do Estado, (ZIPPELIUS, 1997, p. 139) considera que a origem do Estado pode ser identificada na teoria patriarcal, na teoria patrimonial, na teoria do poder e numa teoria contratual historicamente entendida. Independentemente de qual seja a teoria adotada, entendemos que não haverá impacto no desenvolvimento da análise do tema central, partindo do pressuposto de que o mote a ser abordado independe da do caminho de formação estatal.

${ }^{5}$ Não deixamos de acreditar que o positivismo contribui sobremaneira para a Teoria do Bem Jurídico, mas entendemos, com Binding, que há desvinculação entre a lei e a norma penal, de sorte que esta última, antes de jurídico-positiva, é jurídico-racional. In: PLANAS, Ricardo Robles; BRANDÃO, Cláudio (Coord.). Estudos de dogmática jurídico penal: fundamentos, teoria do delito e direito penal econômico. Belo Horizonte: 2016, p. 44.
} 
é o ramo que mais carece de uma estrutura sólida de justificação, fundamentação e legitimação, dado o seu objeto de incidência e as consequências que impõe. De fato,

Quando se fala em direito penal pensa-se logo em fatos humanos classificados como delitos; pensa-se, igualmente, nos responsáveis por esses fatos - os criminosos - e, ainda, na especial forma de consequências jurídicas que Ihes estão reservadas - a pena criminal e a medida de segurança 6 .

Com efeito, a importância do Direito Penal, que compõe essa necessidade especial de justificação e legitimação, guarda estreita relação com seu objeto ${ }^{7}$, que se eleva à condição de bem jurídico, cuja carência de tutela passa necessariamente pela restrição da ultima ratio característica desse ramo do Direito ${ }^{8}$. Embora a figura do bem jurídico tenha ganhado contornos mais precisos nos ordenamentos contemporâneos, sua importante função é historicamente percebida; conforme ensina Bechara9 ${ }^{9}$ :

O surgimento da teoria do bem jurídico insere-se no pensamento desenvolvido sob a influência da Restauração e consubstanciado na reação contra a ideologia iluminista, a partir do desencantamento com o racionalismo especulativo, da preocupação com a insegurança jurídica e do despertar de um sentido histórico positivista.

Se de um lado o Direito Penal é imbuído dessa excepcionalidade, de outro não há dúvida de que a Culpabilidade é um dos seus institutos que mais se dá ao fim de justificar e legitimar, uma vez que:

El principio de culpabilidad tiene que ver con la justificación de la imposición de la pena a individuos concretos (distribución de las penas), es decir, con la carga que tiene el Estado de Derecho de ofrecer frente a todo ciudadano una legitimación del mal o restricción de derechos que se le impone con base en un hecho que ha cometido ${ }^{10}$.

Todavia, apesar da busca incessante do aprimoramento dogmático, falar em Culpabilidade é ainda hoje pisar em terreno arenoso, devendo-se à sua complexidade

\footnotetext{
${ }^{6}$ TOLEDO, Francisco de Assis. Princípios básicos de direito penal, 5a ed. São Paulo: Saraiva, 1994, p. 1.

7 PLANAS, Ricardo Robles; BRANDÃO, Cláudio (Coord.). Estudos de dogmática jurídico penal: fundamentos, teoria do delito e direito penal econômico. Belo Horizonte: 2016, p. 46

${ }^{8}$ Ultima ratio entendida em sentido duplo: a lei penal pode reagir somente frente ao que já é em si um injusto $e$ conforme determinados critérios de seleção dos injustos que devem ser punidos penalmente. Cf. PLANAS, Ricardo Robles; BRANDÃO, Cláudio (Coord.). Estudos de dogmática jurídico penal: fundamentos, teoria do delito e direito penal econômico. Belo Horizonte: 2016, p. 44.

${ }^{9}$ BECHARA, Ana Elisa Liberatore Silva. Bem jurídico-penal. São Paulo: Quartier Latin, 2104, p. 93.

${ }^{10}$ FEIJÓO SÁNCHEZ, Bernardo José. Culpabilidad jurídico-penal y neurociencias. In: CRESPO, Eduardo Demetrio (Dir.); MAROTO CALATAYUD, Manuel (Coord.). Neurociencias y derecho penal: nuevas perspectivas en el ámbito de la culpabilidad y tratamiento juridico-penal de la periculosidad. Montevideo: B. de F., 2013, p. 269.
} 
e intangibilidade a maior dificuldade de estabilização de seu conteúdo e, para as mais variadas teorias que a abordam, a de se blindar a críticas e se manter no tempo.

Comumente, na construção conceitual da Culpabilidade, autores partem de suportes filosóficos, políticos e mesmo religiosos, com abstrações tais de pensamentos que se pode pressupor a sua sobrevivência tão-somente até o momento em que outra reflexão, muitas vezes influenciada pela conveniência de política criminal, tome-lhe a vez.

De fato, pode-se identificar que, ao longo de muitos anos, esses ramos de estudo têm guardado umbilical ligadura com as ciências sociais, como o Direito, que delas se sorvem de infinitos conceitos para direcionar o regramento que se diz indispensável à convivência social. Afinal, como bem pontua Aníbal Bruno ${ }^{11}$,

\begin{abstract}
Não pede o jurista justificação para o Direito. Toma o sistema jurídico e as suas implicações como uma realidade que existe e exerce a sua função normativa prescindindo de qualquer indagação de legitimação. A Filosofia é que opõe a essa posição empírica uma exigência de justificação racional, que acompanha toda construção jurídica, do mesmo modo que outras instituições sociais, e faz transpor conclusões da sua atividade especulativa ao domínio do Direito. E não se pode negar importância a essas conclusões na construção do Direito Penal e dos seus diversos institutos.
\end{abstract}

A despeito de ser destinado específico espaço na presente monografia para os conteúdos que dão suporte à Culpabilidade - sejam eles dogmáticos, filosóficos ou mesmo religiosos - é certo que uma figura ganha especial destaque por sua altivez e manutenção no tempo para a finalidade a que se presta. Trata-se, como se disse, do livre-arbítrio, um importante conceito trasladado ao Direito Penal a partir da filosofia e da religião com o objetivo exatamente de preencher o conteúdo da Culpabilidade, sem o qual seria difícil justificar a intervenção penal do Estado na vida de seus cidadãos. Não é demais ter em ciência que

A questão do livre arbítrio, ou da liberdade da vontade, é central tanto na Filosofia quanto no Direito penal. Neste, em especial dentro da culpabilidade, mas também quando se comenta a função da pena, jamais foi raro que viesse o tema à tona, ainda que fora para afirmar simplesmente que a discussão acerca dele deva restringir-se a bizantinas discussões filosóficas ${ }^{12}$.

\footnotetext{
${ }^{11}$ BRUNO, Anibal. Direito penal, parte geral, tomo 3: pena e medida de segurança, 4⿳⺈ ed. Rio de Janeiro: Forense, 1978, p. 30.

${ }^{12}$ RODRÍGUEZ, Víctor Gabriel. Livre Arbítrio e Direito Penal: Revisão frente aos aportes da neurociência e à evolução dogmática. Tese de Livre-Docência. Universidade de São Paulo, 2014, p. 15.
} 
É evidente que a ação humana, considerada desde um aspecto livre e consciente, é o alicerce que justifica a imputação da responsabilidade individual e, conseguintemente, é também um dos elementos que permitem ao Estado gerar a correspondente consequência negativa acerca de uma conduta tida como desviante. Não fosse a aceitação da existência do livre-arbítrio, a intervenção baseada na Culpabilidade seria ilegítima, senão injusta.

Por esse motivo, as liberdades de vontade e de agir, em paralelo à especulação de outros ramos do conhecimento, importam em grande medida ao próprio Direito, e em especial ao Direito Penal, em cuja seara o Estado se revela em sua face mais agressiva. Como pontua Manzano (2013, p. 105),

\begin{abstract}
La polémica acerca de si el actuar humano es libre o está determinado constituye una de las cuestiones esenciales sobre las que todo penalista ha reflexionado en algún momento de su vida profesional. El penalista, como cualquier persona, se siente fascinado por las cuestiones existenciales, que, como ésta, parecen exceder a la propia comprensión humana (...).
\end{abstract}

É que, num Estado Democrático de Direito, a responsabilidade penal do indivíduo sobre suas condutas reside exatamente na ideia de que a ele foi dada a escolha acerca da forma como agir, uma vez que é considerado senhor de si, possuidor de uma liberdade de querer que, no gozo de suas plenas faculdades mentais, torna-o definitivamente a causa primordial da conduta praticada, levada como exteriorização de sua vontade ${ }^{13}$.

Embora o presente trabalho pretenda desenvolver as questões adjacentes ao tema, pode-se afirmar que o livre-arbítrio é de fato um postulado razoavelmente estável e que tem possibilitado ao longo dos tempos certa aceitação do modo como se dá a distribuição da responsabilidade penal, sendo uma importante base da Culpabilidade.

Pode-se afirmar, pois, que o grande campo do presente estudo é exatamente a Culpabilidade e seu pressuposto do livre-arbítrio, sem se olvidar, obviamente, de outros conceitos que no decorrer dos anos têm alimentado referido instituto e explicado o postulado da liberdade.

\footnotetext{
${ }^{13}$ Não se olvida, mas também não se toma em plano introdutório, as questões relacionadas a exclusões de culpabilidade que, ao fim e ao cabo, são também limitações ou exclusões da própria liberdade.
} 
Em uma gradação de três níveis, o segundo ponto da análise passará pelo enfrentamento do livre-arbítrio a partir dos experimentos neurocientíficos de Benjamin Libet, que configurarão o ponto de questionamento sobre a validade dos atuais entendimentos da livre vontade.

Sob o ponto de vista neurocientífico, tem-se por objetivo abordar dois aspectos de relevo: o questionamento sobre a validade do pressuposto do dualismo cartesiano $^{14}$, de um lado, com sua consequente consideração de um possível determinismo, e a projeção das consequências penais sobre sua aceitação, de outro.

Com efeito, é mister enfrentar a questão relacionada à suposta metafísica da mente que, a nosso ver, é o ponto gerador das abstrações tamanhas da filosofia e da religião acerca da livre vontade. No ponto, parece ser exatamente essa imaterialidade que permite os discursos de autodeterminação suprema e, portanto, consente que a distribuição da culpa se dê como se dá.

Ocorre que, para alguns neurocientistas extremados, e de certo modo o próprio Libet inicialmente, a partir de estudos que vêm sendo desenvolvidos nas últimas décadas, é possível supor que a liberdade de agir, com sua característica metafísica, não passe de uma ilusão construída a partir de conceitos abstratos, imprecisos e, principalmente, não demonstráveis.

Os métodos de algumas linhas das Neurociências, como a de Libet, - e que também será alvo de questionamentos - teriam a credibilidade aumentada exatamente por serem pautados em experimentos científicos, que têm o condão de demonstrar, em afirmações comprováveis, a validade de suas hipóteses. Isto é, tratase de verdadeira contraposição em relação à abordagem feita pela filosofia, pela religião etc.

Com efeito, tem-se que a liberdade de vontade, de decisão e de ação do ser humano, de acordo com os estudos oriundos das Neurociências, se dá de modo totalmente diferente daquele considerado pelas especulações levadas a efeito, sobretudo, pela Filosofia.

\footnotetext{
${ }^{14}$ Fala-se, igualmente, em dualidade, a qual, apesar de certa diferença em relação ao dualismo cartesiano, parte igualmente da premissa da existência do material e do imaterial na formação do ser humano.
} 
Em capítulo próprio, os questionamentos concernentes ao conceito de livrearbítrio vigente no meio jurídico será contraposto com algumas das especulações científicas de Benjamin Libet, cujos ensaios concluem que há atividade cerebral inconsciente que influenciaria (ou condicionaria) a vontade, decisão e ação humanas, porquanto antecedente da atividade consciente.

Libet denominou esse intervalo entre as atividades inconsciente e consciente de Potencial de Disposição (Readiness Potential) e a considera ponto fulcral de seus experimentos:

\begin{abstract}
The long time interval (averaging about $800 \mathrm{~ms}$ ) by which RP onset preceded a self-paced act raises the crucial question whether the conscious awareness of the voluntary urge to act likewise appears so far in advance. If a conscious intention or decision to act actually initiates a voluntary event, then the subjective experience of this intention should precede or at least coincide with the onset of the specific cerebral processes that mediate the act ${ }^{15}$.
\end{abstract}

Essa conclusão inicial dá o tom da longa discussão sobre o livre-arbítrio e um suposto determinismo, que poderia, em situações extremas, negar totalmente a existência da livre vontade: o indivíduo como senhor de si de outrora passaria a ser não mais que um produto, um objeto de seu cérebro, que age independentemente de sua intenção consciente no processo volitivo.

Admitir que todo o processo envolvendo as condutas e seu entorno tem caráter unicamente material, como algumas linhas o tem feito, significa, também, a possibilidade de estudá-lo empiricamente, assim como possivelmente comprovar os dados de estudo, o que representa de fato uma nova luz em ambiente deveras obscuro.

Diferentemente dos estudos levados a efeito sobre o tema até o início do século XX, nas mais das vezes especulativos, a evolução das Neurociências, possibilitada pela criação e aperfeiçoamento de inúmeros modernos instrumentos de acesso ao cérebro, tem desafiado tudo o que até então se conhecia sobre o seu funcionamento.

\footnotetext{
${ }^{15}$ LIBET, Benjamin. Unconscious cerebral initiativeandthe role ofconsciouswill in voluntaryaction. In: The BehavioralandBrainSciences, New York : Cambridge University Press, 1985, year 8, n. 4, p. 529.
} 
Isto corresponde a uma diametral diferença do ponto de partida da filosofia e da religião, que sempre trataram do assunto desde uma perspectiva especulativa e metafísica, servindo de fundamentação à Culpabilidade, ainda que a mesma atualmente também se caracterize por conceitos dogmáticos e normativos.

Com efeito, as Neurociências passam a questionar sólidos conceitos, construídos ao longo dos séculos, mormente no que concerne ao dualismo cartesiano, uma vez que, para parte de seus teóricos, a constituição do ser humano, inclusive no que toca às tomadas de decisões, pode ser identificada única e exclusivamente por seu corpo (matéria), deixando de lado a ideia de mente como algo imaterial.

Não é de se olvidar, nessa linha, que jamais se pretende dar fiabilidade máxima às Neurociências, sobretudo pela amálgama de suas conclusões. Mas também não se pode manter o Direito apartado dessas mesmas conclusões: há necessidade de que Direito, Ciências e Filosofia se entendam, na medida do possível. Como escreveu CRESPO (2014, p. 18):

Tudo parece indiciar que, por muito que forcemos os limites do raciocínio, a
técnica dogmática por si só não terá o rendimento desejado, pelo que,
repetidamente, terá que elevar a vista algo mais além e contemplar os
problemas com uma maior amplitude, não passivamente desde uma cômoda
torre de vigia, mas com a imprescindível ajuda que oferece a Filosofia. Como
tratarei de demonstrar, nem as Neurociências, como ciências empíricas, nem
o Direito penal, como ciência social, podem prescindir dela e estão, portanto,
obrigados a entender-se.

De fato, não é questão de destituir os avanços que as próprias especulações filosóficas possibilitaram, mas sim de se questionar a possibilidade de se admitir que as ciências empíricas deitem sombra no Direito como a própria Filosofia o faz. Pode nos parecer verdadeiro conservadorismo negar tal influência sob a justificativa de que o Direito tem por objeto "verdades formais", "normativas", "não verificáveis empiricamente".

De igual modo, a normatividade não deve ser imune à ciência simplesmente em virtude de a expectativa de que o êxito de determinada teoria empírica colocaria em xeque as edificações jurídicas, inviabilizando-as. Talvez, se inviabilizadas forem, seja porque já não servem para seu mister; ao menos, não desde um ponto de vista legítimo. 
Nesse ponto, é importante a leitura de $\mathrm{CRESPO}^{16}$, quem faz uma análise do que resultaria ao Direito Penal em sede de eventual reconhecimento de um determinismo forte: Um Direito Penal de medidas? Um Direito Penal Totalitário? Um Direito Penal Impraticável?

A reformulação do Direito Penal, seja a que custo dogmático for, pode não ser tão cara quanto a sua manutenção sobre bases insólitas, sob uma falsa percepção de que há legitimidade nas colunas que o sustentam.

Esclareça-se, também desde já, que não tem a presente monografia qualquer conotação abolicionista, sobretudo por fugir-lhe do escopo, de modo que passará distante de qualquer conclusão nesse sentido.

O estudo, perpassando pelas análises de áreas do conhecimento humano que de modo significativo utilizam-se da liberdade como objeto de análise, desembocará nos estudos neurocientíficos de Libet para deles servir-se como ponto de questionamento, sem contudo concluir categoricamente sobre a validade de seus métodos e conclusões; afinal, além da especificidade da área, basta ao objetivo da monografia os avanços e conjecturas de suas análises, que têm feito balançar a ideia de liberdade tal qual se tem utilizado o Direito Penal.

É que, como se espera demonstrar, a estruturação da liberdade a partir do conhecimento neurocientífico tem colocado em especial questionamento o modo como se dá a interferência estatal por meio do Direito Penal, cujas premissas poderão sofrer consideráveis modificações no futuro, ao menos no intuito de imbuir-se de legitimidade suficiente à sua subsistência.

Assim, mostrar-se-á a contribuição neurocientífica de Libet para uma análise neurobiológica do movimento de tomada de decisões e das próprias ações, ou seja, o reconhecimento de processos bioquímicos que antecedem o agir humano e o podem condicionar, ao menos em certa medida, colocando em dúvida o pensamento cartesiano sobre a existência da mente como algo imaterial e distinto do próprio corpo.

Importa observar, todavia, que a abordagem não necessariamente depende da abolição da ideia do dualismo cartesiano como apregoam os deterministas fortes,

16/bidem, p. 31-32. 
de modo que é possível aceitar ainda as posições literárias dos dualistasinteracionistas ou integrais. O que dá o tom da monografia, em verdade, é algo de certo modo aceito por estes últimos: o fato de que o processo de tomada de decisão depende, seja em que grau for, da atividade cerebral consciente e, de acordo com os neurocientistas, também da inconsciente.

Ou seja, atualmente divide-se com muito mais facilidade a responsabilidade pelo processo volitivo entre a mente e o próprio funcionamento cerebral, em se tratando de pessoas saudáveis. O ponto de conexão que nos interessa, então, é a parcela atinente ao funcionamento bioquímico do cérebro, a possibilidade de se alçar o determinismo material, ainda que moderado, à condição de objeto de especulação sobre o processo volitivo.

Não é preciso dizer que a constatação dessa atividade cerebral inconsciente, capaz de questionar a liberdade tal qual entendemos atualmente, terá grande influência no campo da Culpabilidade penal. Mas, para além dessa questão, a presente monografia visa a questionar até que ponto as Neurociências têm razão e qual seria a repercussão na distribuição da culpa.

É que, com a justaposição do processo de tomada de decisão à atividade material do cérebro, ou seja, se deixada de lado qualquer ideia puramente metafísica da mente, passar-se-ia a questionar se maior razão assiste às teorias que veem no Estado uma das principais causas de predisposição social de um indivíduo à prática criminosa.

Com o cuidado de não se alinhar a indesejáveis segregacionismos de teorias de evolucionismo social darwiniano, o estudo visará a buscar fundamento e a justapor o indivíduo - ou melhor, a constituição da atividade cerebral - em sua possível sujeição às condições sociais estimuladas pela organização da coletividade, no caso possibilitadas pelo próprio Estado.

A importância da análise reside no fato de que o pressuposto e ponto de encontro inaugurados pelas neurociências, ou seja, a composição material da atividade cerebral no que toca ao processo volitivo, não seria possível senão em decorrência da negação da ideia de metafísica pura consubstanciada no dualismo cartesiano. 
De fato, a clássica divisão cartesiana entre corpo e mente tem pautado sobremaneira a discussão sobre a livre vontade há muito tempo, podendo-se afirmar que serviu como teoria apaziguadora, porquanto convergente, entre diversos pensamentos acerca do tema. Essa façanha, podemos dizer, se deu em boa parte devido à desnecessidade de se comprovar a existência da mente, que goza de grande aceitação no plano teórico.

Com as Neurociências, contudo, esse dualismo começa a ceder espaço para outras formas de abordagem da questão. Sem prejuízo da discussão acerca das construções filosóficas e religiosas sobre o assunto, que se vestiram de enorme importância ao longo dos séculos, não há dúvida de que a limitação do acesso aos recônditos detalhes do funcionamento cerebral foi a maior causa da aceitação das teorias metafísicas.

Por fim, é de se dizer que toda a problemática no entorno da Culpabilidade, aí se incluindo aquela trazida pelas Neurociências, hão de merecer toda a atenção por parte dos estudiosos. Afinal, como disse Mezger (1935, p.41), o problema da culpabilidade é o problema do destino mesmo do direito de castigar. 


\section{Conclusão.}

A par de todo o quanto ora delineado na presente dissertação, resta-nos a questão inicial, que movimentou a pesquisa acerca dos temas expostos: é possível a compatibilização entre as proposições neurocientíficas iniciais de Benjamin Libet e a legitimação da aplicação da pena tendo a Culpabilidade como condição e o livrearbítrio como pressuposto?

Embora as proposições de Benjamin Libet não configurem um determinismo propriamente dito, haja vista admitir, especialmente após seu segundo experimento, de 1999, a existência do livre-arbítrio, entendemos que as atuais afirmações do neurocientistas, se elevadas à categoria de fato científico, deveriam implicar em consequências à Culpabilidade, uma vez que, com o deslocamento temporal da atuação do livre-arbítrio, sobretudo com a antecedente existência do Readnesse Potential no sentido por ele delineado, inevitavelmente causariam uma modificação no raciocínio jurídico acerca da distribuição de culpa e responsabilidade.

Como se sabe, o instituto da Culpabilidade tem funções múltiplas, sendo uma delas a diferenciação casual, individual, da responsabilidade por fato penalmente relevante. E é exatamente nesse contexto que as hipóteses de Libet se encaixariam de forma a necessitar uma mudança do que se compreende e de como se vincula a culpa a um indivíduo.

Como já discorrido anteriormente, sendo a iniciação causal de um resultado desvinculada do livre-arbítrio, que passa a ter uma função - ainda que determinante - de veto ou concordância com a causa inicial, distinguir a natureza dessa inclinação inaugural reveste-se de importância suprema na configuração da culpa, assim como o detalhamento do poder de veto proposto.

Infelizmente ainda não existem meios de se apurar tais fatores, mas desde já é de se admitir que, uma vez que se chegue à elucidação dessas questões, a comunidade jurídico-penal deve comunicar-se com as Neurociências no intuito de desempenhar seu principal papel ante a intervenção do Estado na esfera privada da vida individual. 
Assim, partindo do pressuposto de que a intenção inconsciente guarda estreita relação com o sentido do comando cerebral acerca de uma decisão a ser tomada, será imperativo reconhecer que o sentido dessa inclinação importará de plano para a superveniência da conduta executada. Ou seja, será de rigor admitir que o comando inicial estará no sentido positivo ou negativo de determinada (in)ação.

Consequentemente, em um primeiro momento, bipartindo a análise da culpabilidade de modo a adequar a distribuição de culpa a cada indivíduo, poderá surgir a necessidade de que sua atuação inicie exatamente no sentido da inclinação inconsciente dada pelo cérebro: tomando-se a conduta " $x$ " como sendo penalmente relevante, no aspecto de ferir um bem jurídico e ocasionar a imposição de uma sanção penal, e tendo ela sido praticada por duas pessoas mentalmente capazes, haveria diferenciação se elas "vetaram" ou "aceitaram" a inclinação inconsciente? Veja-se.

Tício praticou a conduta " $x$ ", quando o impulso inconsciente era de que praticasse mesmo essa conduta, apenas não a tendo vetado.

Caio, por seu turno, também praticou a conduta "x", embora seu cérebro tivesse inicialmente uma inclinação à conduta "y", irrelevante ao Direito Penal, de modo que ele a tenha vetado.

Afora os critérios já utilizados pelo Direito Penal em sede de Culpabilidade para a individualização da pena, parece-nos, em princípio, haver relevância penal na natureza do impulso neurobiológico em direção a uma conduta ou outra, uma vez que sobre ele é que agiria o livre-arbítrio diferido sugerido por Libet.

De fato, no exemplo acima, não nos afigura correto que o Direito Penal ficasse indiferente e não houvesse diferenciação decorrente da constatação de que Tício "aceitou" o impulso inconsciente de uma conduta socialmente indesejada enquanto 
Caio praticou essa mesma conduta, mas em consequência de ter vetado uma (in)ação irrelevante ao Direito Penal, contrariando o comando inconsciente.

Evidentemente que essa análise apenas fará sentido e será necessária a partir de sua conjugação com o fato relacionado ao "poder de veto". A conclusão até o momento simplista de que o exercício do livre-arbítrio é causa final e determinante da exteriorização das condutas humanas parece servir à conjuntura social existente, não se dando relevo à investigação acerca de sua capacidade frente à atuação neuronal inconsciente.

Todavia, a pura anotação de escolha livre e consciente entre possibilidades distintas, sendo a principal delas, nessa análise, o impulso antecedente e inconsciente do cérebro, muda a concepção então vigente do livre-arbítrio como fonte inicial e final do exercício cerebral. Escolher há de ser diferente de criar esse mesmo algo, ainda que ele se opere em estágio inconsciente. Por isso, também, em nossa visão a percepção subjetiva da autonomia pode não ser suficiente à Culpabilidade.

Com efeito, para que os atuais estudos e Libet possam exercer algum contato efetivo com a Culpabilidade, entendemos que estudos supervenientes precisariam explicar a influência dos impulsos neurobiológicos inconscientes sobre o poder de veto, ou, em outro sentido, se essa capacidade de veto é igual em todos os indivíduos e se seria capaz de se manter totalmente imune ao comando inconsciente.

Em termos filosóficos, parece-nos evidente, numa relação de causa efeito, que se a um indivíduo é dado um fator sobre o qual decidir, se lhe é contraposta um inclinação em determinada direção, haverá um ponto, ainda que não determinante, a gerar efeitos dele mesmo indissociáveis.

Importante, notar, no entanto, que essas possíveis novas bases de cunho neurocientífico, à luz dos experimentos de Benjamin Libet, não alterariam drasticamente a justificativa penal na distribuição de culpa e imposição de pena, senão alterariam ou aperfeiçoariam aquilo que já se tem como objetivo central da Culpabilidade, com a distinção precisa do valor da reprovabilidade da conduta. Até aqui, estamos de acordo com Crespo, para quem

É improvável que a chamada "revolução neurocientífica" leva consigo uma "mudança de paradigma" cultural no sentido do pensamento "kuhniano" sobre o desenvolvimento científico (Kuhn, 1976) que faça tremer os princípios 
jurídicos fundamentais. Isto não significa, porém, que não se deva estar alerta ante a evolução que possa chegar a produzir-se porque os eventuais efeitos positivos podem também converter-se em enormemente perniciosos se não aprendermos as lições do passado ${ }^{195}$.

Isso está em consonância com a natureza própria do instituto, que trabalha com aspectos subjetivos da prática de uma conduta, de modo que, havendo avanço em áreas adjacentes a esse tema, não pode ele ficar imune às suas consequências. 


\section{Bibliografia.}

AGOSTINHO, Santo. O livre-arbítrio, tradução, organização, introdução e notas de de Nair de Assis Oliveira; revisão de Honório Dalbosco. São Paulo: Paulus, 1995.

AGUSTíN, San. Obras completas de San Agustín, XL. Traducción Teodoro C. Madrid. Madrid: Biblioteca de Autores Cristianos, 1995.

AUGUSTINUS. Retratactionum libri I (XXVI, 55c-70d). A. Mutzenbecher (ed.), Corpus Christianorum, Series Latina LVII.

AGUIAR, Renan; RODRIGUES MACIEL, José Fabio (coord.). História do direito. São Paulo: Saraiva, 2008, $2^{\mathrm{a}}$ ed.

BATISTA, Nilo. Matrizes ibéricas do sistema penal brasileiro - I. Rio de Janeiro: Freitas Bastos, 2000.

BEAR, Mark F [et. al.]. Neurociências: Desvendando o Sistema Nervoso. Porto Alegre: Artmed Editora, 2017, $4^{\mathrm{a}}$ ed.

BECHARA, Ana Elisa Liberatore Silva. Bem jurídico-penal. São Paulo: Quartier Latin, 2104

BINDING, Karl. La culpabilidad en derecho penal. Montevideo-Buenos Aires: BdeF, 2009.

BITENCOURT, Cezar Roberto. Tratado de direito penal: parte geral, 17ª ed. São Paulo: Saraiva, 2012

BOBBIO, Norberto. Igualdade e liberdade. Rio de Janeiro: Ediouro Publicações S.A, 1996.

BOÉCIO. A consolação da filosofia. São Paulo: Martins Fontes, 2016

BRANDÃO, Cláudio. Curso de Direito Penal, parte geral. Rio de Janeiro: Forense, 2008. 
BRUNO, Anibal. Direito penal, parte geral, tomo 3: pena e medida de segurança, $4^{a}$ ed. Rio de Janeiro: Forense, 1978.

COELHO, Jonas Gonçalves. Livre-Arbítrio e a relação mente e cérebro em Benjamin Libet. - Principia 18(1): 153-174 (2014). Published by NEL - Epistemology and Logic Research Group, Federal University of Santa Catarina (UFSC).

CORDEIRO, Mário. Príncipes da medicina. Lisboa: Editora Saída de Emergência, 2016.

CRESPO, Eduardo Demetrio. Compatibilismo humanista: uma proposta de conciliação entre neurociências e direito penal. In BUSATO, Paulo Cesar (org.) Neurociências e direito penal. São Paulo: Atlas, 2014.

CRESPO, Eduardo Demetrio in Neurociencias y Derecho penal: nuevas perspectivas en el ámbito de la culpabilidad y tratamiento jurídico-penal de la periculosidad.Demetrio Crespo, Eduardo (dir.) MarottoCatalayud, Manuel (coord.). Montevideo: B. de F., 2013.

CHAUÍ, Marilena. Convite à Filosofia. São Paulo: Ed. Ática, 2000.

ESTEFAN, André. Direito Penal, vol. 1. São Paulo: Editora Saraiva, 2010.

FEIJÓO SÁNCHEZ, Bernardo José. Culpabilidad jurídico-penal y neurociências. Buenos Aires: BdeF, 2013.

FERRAZ JUNIOR, Tercio Sampaio. Introdução ao estudo do direito: técnica, decisão, denominação, 4⿳亠丷a ed. São Paulo: Atlas, 2003.

FERRI, Enrico. Princípios de direito criminal. Campinas: Bookseller, 1996

FILHO, Marco Aurélio. Culpabilidade - Crítica à presunção absoluta do conhecimento da lei penal. São Paulo: Saraiva, 2017.

FINGER, Stanley. Origins of Neuroscience. New York: Oxford University Press, 1994. 
FONSECA, João José Saraiva. Metodologia da pesquisa científica. Fortaleza: UEC, 2002.

FLORÊNCIO FILHO, Marco Aurélio. Culpabilidade: crítica à presunção absoluta do conhecimento da lei penal. São Paulo: Editora Saraiva, 2017.

FRAGOSO, Heleno Cláudio. Lições de Direito Penal. Rio de Janeiro: Editora Forense, 1986, $10^{\circ}$ ed..

GOTTSCHALL, Carlos Antonio Mascia. Medicina hipocrática : antes, durante e depois. - Porto Alegre: Stampa, 2007.

HERRERA, Lucio Eduardo. El error en materia penal. Buenos Aires: AbeledoPrerrot, 1971.

HUNGRIA, Nelson. Comentários ao código penal, vol. I, tomo II, 4⿳亠丷a ed. - Rio de Janeiro: Forense, 1959.

JIMÉNEZ DE ASÚA, Luis. Tratado de Derecho Penal, tomo I. Buenos Aires: Losada, 1950.

JUNQUEIRA, Gustavo Octaviano Diniz. Direito Penal, 8ª ed. São Paulo: Premier Máxima, 2009.

KANT, Immanuel. A metafísica dos costumes - contendo a doutrina do direito e a doutrina da virtude. Trad. BINI, Edson. Bauru/SP: Edipro, 2003.

KIM, Douglas. O livro da filosofia, $2^{a}$ ed. São Paulo: Globo Livros, 2016.

LOPES, José Reinaldo de Lima. O direito na história. São Paulo: Atlas, 2008.

LIBET. Benjamin. Do We Have Free Will?. Journal of Consciousness Studies, 6, no 8-9, 1999. Disponível em: <https://bit.ly/2kalw8e>. Acesso em abril 2019.

LIBET, Benjamin. Unconscious cerebral initiative and the role of conscious will in voluntary action. New York: Cambridge University Press, 1985, year 8, n. 4.

LISZT, Frans Von. Tratado de Direito Penal Alemão. Brasília: Conselho Editorial do Senado Federal, 2006.

LISZT, Franz von. La idea del fin em el derecho penal. Granada: Comares, 1995. 
MALINOWSKI, Bronislaw. Crime and Custom in Savage Society. New Jersey: Rowman \& Allanheld Publishers, 1985.

MALINOWSKI, Bronislaw. Crime e castigo na sociedade selvagem. Brasília: Editora Universidade de Brasília, 2003.

MEZGER, Edmundo. Derecho Penal, tradução de José Arturo Rodriguez Muñoz Tomo II. Madrid: Ed. Rev. Direito Privado, 1935.

MUNHOZ NETTO, Alcides. A ignorância da antijuridicidade em matéria penal. Rio de Janeiro: Forense, 1978.

NORONHA, E. Magalhães. Direito Penal, vol. 1 - São Paulo: Saraiva, 1997.

PAGLIUCA, José Carlos Gobbis. Direito Penal - Parte geral, 3 ed. São Paulo: Rideel, 2007.

PÉREZ MANZANO, Mercedes. El tiempo de la conciencia y la libertad de decisión: bases para una reflexión sobre neurociencia y responsabilidad penal. Buenos Aires: BdeF, 2013.

PLANAS, Ricardo Robles; BRANDÃO, Cláudio (Coord.). Estudos de dogmática jurídico penal: fundamentos, teoria do delito e direito penal econômico. Belo Horizonte: 2016.

PLATÃO. As Leis, Livro IX. São Paulo: Edipro, 2010.

PLATÃO. A República, $\mathbf{6}^{\circ}$ ed. Ponta Grossa: Ed. Atena, 1956.

PLATÃO. Vida e Obra. Coleção "Os Pensadores". São Paulo: Editora Nova Cultural Ltda., 1999

PRADO, Luiz Regis. Curso de Direito Penal Brasileiro, vol. 1 - Parte geral: arts. 1 a 120, 3 ed., rev., atual. e ampl. São Paulo: Editora Revista dos Tribunais, 2002.

RASSI, João Daniel. Neurociência e prova no processo penal: admissibilidade e valoração. Tese de Doutorado. Universidade de São Paulo, 2017. 
REBOLLO, Regina Andrés. O legado hipocrático e sua fortuna no período grecoromano: de Cós a Galeno. Scientiæ zudia, São Paulo, v. 4, n. 1, p. 45-82, 2006.

RODER, Carlos David Augusto. Las doctrinas fundamentales reinantes sobre el delicto y la pena en sus interiores contradicciones. Traducido del aleman por Francisco Giner. Madrid: Libreria de Victoriano Suarez, 1876.

RODRÍGUEZ, Víctor Gabriel. Livre Arbítrio e Direito Penal: Revisão frente aos aportes da neurociência e à evolução dogmática. Tese de Livre-Docência. Universidade de São Paulo, 2014.

SANCHEZ, Bernardo Feijó. Culpabilidad jurídico-penal y neurociencias in Neurociencias y derecho penal - Nuevas perspectivas en el ámbito de lá culpabilidad y tratamiento jurídico-penal de la perigosidad. Montevideo: B. de F., 2013.

SANTOS, Boaventura de Souza. Um discurso sobre as ciências na transição para uma ciência pós-moderna. Revista de Estudos Avançados da Universidade de São Paulo, v. 2, n. 2, publicada em 01.08.1988 - São Paulo: 1988.

SILVA SÁNCHEZ, Jesús María. Aproximación al derecho penal contemporâneo, $4^{a}$ ed. Barcelona: Bosch Editor, 1992,

TOLEDO, Francisco de Assis. Princípios básicos de direito penal, 5ª ed. São Paulo: Saraiva, 1994, p. 1.

TELES, Ney Moura. Direito Penal, parte geral - I, 2ª ed. São Paulo, 1998.

VILAVERDE, Carolina. As 8 maiores religiões do mundo. Revista Super Interessante. Disponível em: < http://bit.ly/2k9UTRX>. Acesso em jul. 2019.

WEBER, Max. Metodologia das ciências sociais, $4^{a}$ ed. São Paulo: Cortez Editora, 2001, p. 6.

ZAFFARONI, Eugenio Raul; PIERANGELI, José Henrique. Manual de direito penal brasileiro: parte geral. São Paulo: Editora Revista dos Tribunais, $1997 .$.

ZIPPELIUS, Reinhold. Teoria Geral do Estado. Lisboa: Fundação Calouste Gulbenkian, 1997. 